\title{
Complications following anterior cruciate ligament reconstruction in the English NHS
}

\author{
Simon S. Jameson a, ${ }^{a}$, Daniel Dowen ${ }^{b}$, Philip James ${ }^{c}$, Ignacio Serrano-Pedraza ${ }^{a}$, \\ Mike R. Reed ${ }^{a}$, David Deehan ${ }^{\mathrm{b}}$ \\ a Northumbria Healthcare NHS Foundation Trust, Woodhorn Lane, Ashington, Northumberland, NE63 9JJ, UK \\ ${ }^{\mathrm{b}}$ Newcastle Hospitals NHS Trust, Freeman Road, High Heaton, Newcastle upon Tyne, NE7 7DN, UK \\ c CHKS Healthcare Intelligence Services, 1 Arden Court, Arden Road, Alcester, Warwickshire, B49 6HN, UK
}

\section{A R T I C L E I N F O}

Article history:

Received 5 November 2010

Received in revised form 24 November 2010

Accepted 26 November 2010

Keywords:

Anterior cruciate ligament reconstruction

Complications

Thromboembolism

\begin{abstract}
A B S T R A C T
Unlike the English National Joint Registry (NJR) for arthroplasty, no surgeon driven national database currently exists for ligament surgery in England. Therefore information on outcome and adverse events following anterior cruciate ligament (ACL) surgery is limited to case series. This restricts the ability to make formal recommendations upon surgical care. Prospectively collected data, which is routinely collected on every NHS patient admitted to hospital in England, was analysed to determine national rates of 90-day symptomatic deep venous thrombosis (DVT), pulmonary thromboembolism (PTE) rate, 30-day wound infection and readmission rates following primary ACL reconstruction between March 2008 and February 2010 (13,941 operations, annual incidence 13.5 per 100,000 English population). 90-day DVT and PTE rates were $0.30 \%$ (42) and $0.18 \%$ (25) respectively. There were no in-hospital deaths. $0.75 \%$ (104) of the consecutive patient cohort had a wound complication recorded. $0.25 \%$ (35) underwent a further procedure to wash out the infected knee joint and 1.36\% (190) were readmitted to an orthopaedic ward within 30 days. This is the first national comprehensive study of the incidence of significant complications following ACL surgery in England. This should allow meaningful interpretation of future baseline data supporting the development of a national ligament registry.
\end{abstract}

(C) 2010 Elsevier B.V. All rights reserved.

\section{Introduction}

Annually, around 100,000 primary anterior cruciate ligament (ACL) reconstructions are performed in the US, with this number increasing [1]. Accurate figures for the frequency of such procedures in English practice do not exist, and there remains little information on the epidemiology of post-operative complications. There is a growing awareness of venous thromboembolism (VTE) following orthopaedic surgery, and there are formal recommendations on thromboprophylaxis from the National Institute for Health and Clinical Effectiveness (NICE) following lower limb arthroplasty [2] but no reliable data exists to allow for informed discussion regarding thrombotic risks following modern endoscopic ligament surgery. Indeed a publication entitled 'Complications of arthroscopic reconstruction of the anterior cruciate ligament' specifically failed to discuss rates of VTE or infection post surgery [3]. The reader may therefore draw the conclusion that thrombotic events or infections following arthroscopic ACL surgery do not represent a clinical problem.

ACL reconstruction performed as a day case (less than $24 \mathrm{~h}$ stay) is increasingly being reported in association with accelerated rehabilitation

\footnotetext{
* Corresponding author. 14 Fairwood Park, Marton-in-Cleveland, TS8 9XP, UK. Tel.: +447812603112 .

E-mail address: simonjameson@doctors.org.uk (S.S. Jameson).
}

[4]. Despite this, there have been sporadic reports of VTE complications ranging from documented deep vein thrombosis (DVT) through to fatal pulmonary thromboembolus (PTE) [5]. BASK best practice guidelines state that thromboprophylaxis is unnecessary given the rarity of VTE [6]. This is in no small measure due to the lack of a prospective national database or large series analyses. Our knowledge is confined to individual surgeon case series and highly subjective postal surveys with poor uptake. It is essential for the purposes of making appropriate and informed recommendations on the prevention of complications following ligament surgery that knowledge of relative risk should exist. Moreover, national standard setting, comparison between units, and evidence for future consultant surgeon revalidation are only possible with population-based datasets.

In depth data concerning diagnosis, operation, co-morbidities and post-operative complications is prospectively collected on every NHS patient admitted to hospitals in England (Hospital episode statistics data [HES]) [7]. The risk of VTE following foot/ankle surgery has previously been analysed [8]. From this independent English database we have now analysed data for ACL surgery.

\section{Methods}

Data for English NHS patients (treated in NHS, private or independent sector treatment hospitals) who underwent planned ACL reconstruction between March 2008 and February 2010 were 
collected from the administrative hospital admissions database (HES data). This was augmented with more recent data from the Secondary Users Service (a system that reports and analyses the latest data from NHS units to support planning and commissioning of healthcare provision) [9]. HES covers all admissions to English hospitals providing care for NHS patients and includes fifteen diagnosis fields (coded using the International Statistical Classification of Diseases and Related Health Problems [10th revision], ICD-10 codes), and fifteen surgical procedure fields (coded using Office of Population, Censuses and Surveys Classification of Surgical Operations and Procedures [4th revision], OPCS-4 codes). Within the system, patients are identified by a pseudonymisation identifier created by the Information Centre for Health and Social Care (ICHSC), in order that independent data analysis providers have no access to patient identifiable information [10]. Records belonging to the same patient (defined using a combination of date of birth, sex and postcode) were linked and the number of days between the index operation and any subsequent orthopaedic re-admission to any NHS hospital was collected. Patients with missing dates of operation were excluded. By employing the appropriate ICD-10 or OPCS codes, complication rates were identified. Rates of PTE, symptomatic DVT and all-cause in-hospital mortality within 90 days were established, even if successfully discharged following the primary procedure. Length of stay and readmission within 30 days of the primary procedure were also analysed. Wound infections and haematomas were grouped as 'wound complications'. In addition, deep wound infection (defined as those who returned to theatre for joint washout) were also analysed independently. Age, sex and Charlson score [11] were recorded for each patient. The Charlson co-morbidity index predicts the one-year mortality for a patient who may have a range of co-morbid conditions. Each condition is assigned with a score of 1, 2, 3 or 6 (Appendix 1) depending on the risk of dying associated with this condition. The combined total score is then used to predict patient-specific overall mortality.

CHKS has approval to re-use HES data with the permission of The Health and Social Care Information Centre [12]. Codes are summarised in Appendix 2. Information about the mechanism of injury, the duration of symptoms, severity of damage and the method of reconstruction was not available, due to the nature of this database.

Provider identification numbers, recorded in the HES database, were used to calculate units' yearly volume of ACL reconstructions. Surgical volume was categorised as high ( $>100$ cases per year), mid $(25-100)$ or low $(>3<25)$. In addition, funnel plots (produced in MATLAB) were used to compare individual units with the national baseline (mean) for the adverse outcomes (VTE, re-operation, infection and readmission). These plots are recommended as a graphical aid for institutional comparisons in order to compare proportions and assess association between outcome and volume of cases [13]. Control limits create a funnel around the baseline (mean hospital performance) in order to identify statistical outliers. The score confidence interval as described by Wilson was used to create limits [14]. This prevents spurious ranking of institutions into 'league tables.' For each adverse outcome scatter plots of performance, as a percentage, were generated against the number of cases reported (the denominator for the percentage). 'Population' represents the number of ACLs performed during the study period (two years) in the plots. In this analysis there was no risk adjustment. Units performing less than three per year were excluded from the funnel plot to avoid unnecessary low volume clutter.

Odds ratios (OR) and 95\% confidence intervals [15] were calculated for rates of post-operative complications using the conditions 'age' (categorised as less than twenty, twenty to 30,30 to 40 , or 40 and over), 'sex', 'Charlson score and co-morbidities', 'length of stay' (less than one day, one-two days, more than two days) and 'hospital provider volume' (low, mid and high volume). For each condition, one category was used as a reference compared to which all other categories were compared. Complications tested were VTE within 90 days, any wound complication within 30 days, re-operation for
Table 1

Demographics of patients undergoing anterior cruciate ligament reconstruction in the English NHS (2008-2010).

\begin{tabular}{lc}
\hline & ACL reconstruction $(\mathrm{N}=13,941)$ \\
\hline Age (years, mean and range) & $29.34(8-83)$ \\
Charlson score & \\
0 & $13012(93.3 \%)$ \\
$\geq 1$ & $929(6.7 \%)$ \\
Sex & $2854(20.5 \%)$ \\
Female & $11084(79.5 \%)$ \\
Male & $3(0.0 \%)$ \\
Missing data & $25(0.2 \%)$ \\
Co-morbidities & $38(0.3 \%)$ \\
IDDM & $5(0.0 \%)$ \\
NIDDM & \\
RA & $2681(19.2 \%)$ \\
Length of stay & $11103(79.6 \%)$ \\
$<1$ day & $127(0.9 \%)$ \\
$<2$ days & $2096(15.0 \%)$ \\
Providers (241 units) & $8469(60.7 \%)$ \\
Minimal volume (62 units) & $3249(23.3 \%)$ \\
Low volume (79 units) &
\end{tabular}

$\mathrm{ACL}$ - anterior cruciate ligament, IDDM - Insulin dependent diabetes mellitus, NIDDM non-insulin dependent diabetes mellitus, RA - rheumatoid arthritis, Minimal volume $<3$ ACLs per year, Low volume $-\geq 3<25$ ACLs per year, Mid volume $-\geq 25<100$ ACLs per year, High volume $-\geq 100$ ACLs per year

deep wound infection within 30 days, and orthopaedic readmission within 30 days. The null hypothesis $(\mathrm{OR}=1)$ was tested using the chisquare test (alpha $=0.05$ ) for a $2 \times 2$ contingency table (Table 3 ).

\section{Results}

Table 1 outlines the patient demographics. A total of 13941 ACL reconstructions were performed in the English NHS in the 24-month study period between 2008 and 2010. Data was recorded at 241 units of which 179 performed more than three ACLs per year (accounting for $99.1 \%$ of patients). Mean age was 29.3 years with a range of 8-83.

Fig. 1 displays the spread of cases by age. The majority of patients were fifteen to 45 years of age. Three patients $(0.0 \%)$ under 10 years old and $47(0.3 \%)$ over 65 years underwent ACL reconstruction.

The spread of inpatient stay is shown in Fig. 2. The majority of patients (79.6\%) stayed in hospital for less than two days, although the true day case figure is considerably lower at around $20 \%$. $99 \%$ of patients were discharged within four days.

Table 2 summarises the complications identified during the study period as a percentage of the total group. Within 90 days of ACL reconstruction, there were 67 thrombotic (peripheral and central, non fatal PTE) events in 62 patients. There were no deaths recorded.

It can be seen from Fig. 3 that ACL surgery increases the risk of VTE compared with a control group of non-surgical patients, but remains at approximately $25 \%$ of lower limb arthroplasty rates. When data was analysed for each unit to create funnel plots, no

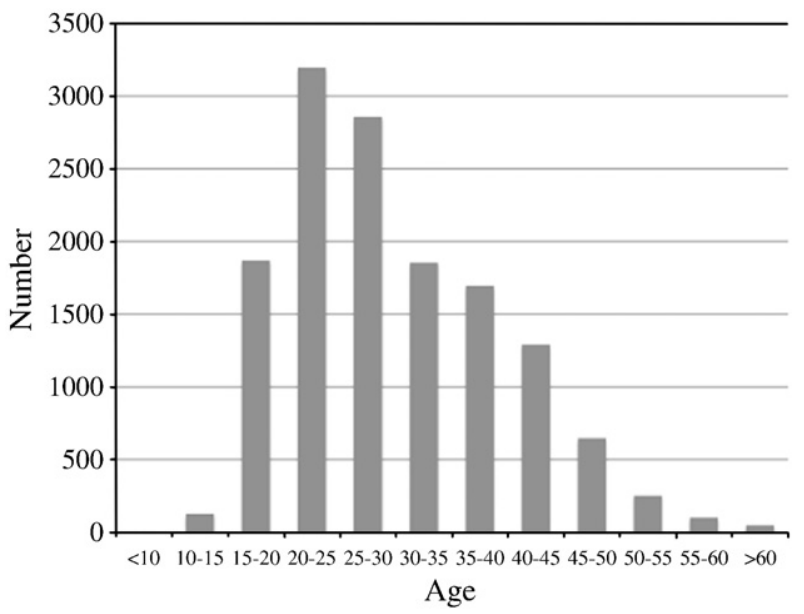

Fig. 1. Age distribution of patients undergoing anterior cruciate ligament reconstruction in the English NHS (2008-2010). 


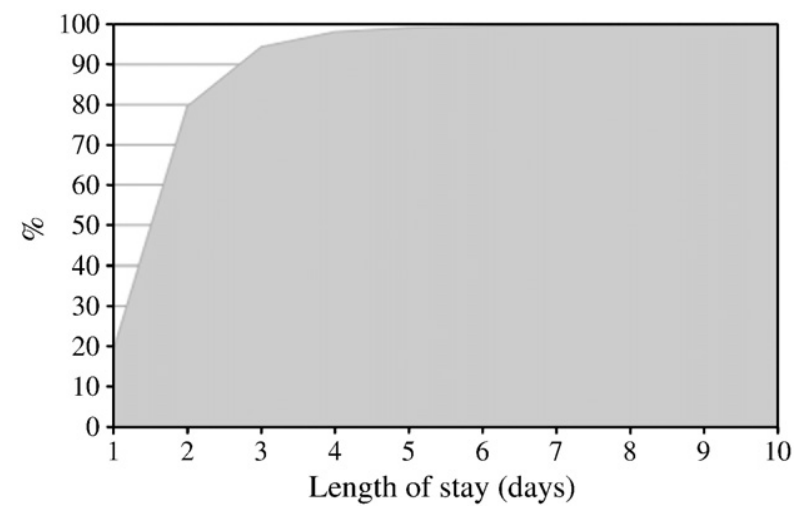

Fig. 2. Length of stay recorded for ACL reconstruction patients in the English NHS (2008-2010).

Table 2

National complication rates following anterior cruciate ligament reconstruction in the English NHS (2008-2010).

\begin{tabular}{lc}
\hline Complication & Number of patients (\%) \\
\hline Any wound complication within 30 days & $104(0.75)$ \\
RTT for deep infection & $35(0.25)$ \\
Orthopaedic readmission within 30 days & $190(1.36)$ \\
Readmission with wound complications & $82(0.59)$ \\
VTE event within 90 days ${ }^{*}$ & $62(0.44)$ \\
DVT & $42(0.30)$ \\
PTE & $25(0.18)$ \\
Death within 90 days & 0 \\
\hline
\end{tabular}

ACL - anterior cruciate ligament, RTT - return to theatre, VTE - venous thromboembolism.

* 5 patients had both DVT and PTE, DVT - deep vein thrombosis, PTE - pulmonary thromboembolism.

outliers were found for VTE rates (Fig. 7). Of the 104 (0.75\%) patients who developed a wound complication within 30 days, $35(0.25 \%)$ required a further operation to wash out the infected knee joint. Figs. 4 and 5 display this data in funnel plots for each unit. There are no outlying units for reoperation for infection. However, there is one high volume unit that falls on the $95 \%$ confidence limits for wound complications.

Fig. 6 shows one outlier (bold square) for 30-day readmission, with several others close to the $95 \%$ confidence line. One hundred ninety patients (1.36\%) were readmitted to orthopaedics within 30 days of discharge. Of these, just under half had a wound complication recorded.

Table 3 shows that the risk of a VTE event was significantly higher in patients 40 years old and over (odds ratio (OR) 2.36, 95\% confidence intervals (CI) 1.29-4.34, $\mathrm{p}=0.004$ ), although length of stay and existing co-morbidities did not appear to have an influence. Male sex was a predictor of 30-day readmission ( $\mathrm{OR}=1.96$ (95\% Cl 1.26-

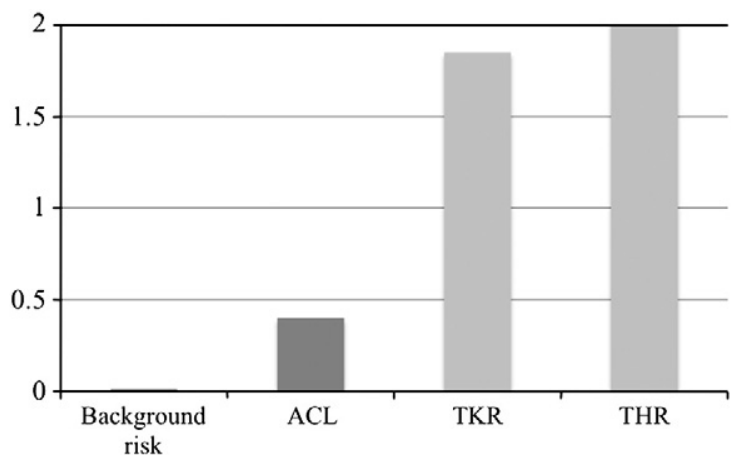

Fig. 3. 90-day VTE rate following ACL reconstruction compared with lower limb arthroplasty and background risk. VTE - venous thromboembolism, ACL - anterior cruciate ligament reconstruction, Background risk in middle-aged, female, non-surgical population [17], TKR- total knee replacement, THR - total hip replacement. VTE risk after THR and TKR [18].

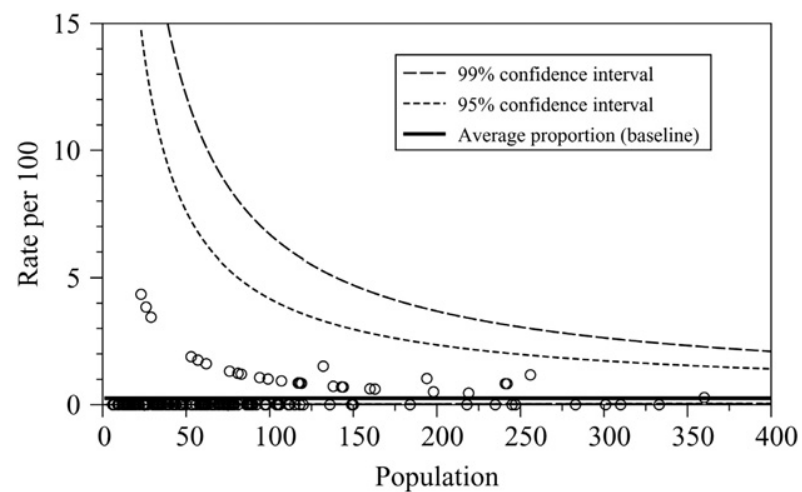

Fig. 4. Funnel plot of 30-day return to theatre for infection following ACL reconstruction in units providing care for English NHS patients.

3.06), inverted from the value in Table 3 , showing the OR for females, $p=0.002$ ). There were no predictors for 30-day wound complication or reoperation for infection.

\section{Discussion}

Anterior cruciate ligament reconstruction is considered a safe procedure performed endoscopically with low complication rates. The literature describes revision rates for graft failure and poor tunnel position but little information on infection and VTE [3]. To the best of our knowledge this is the first independent comprehensive report from an English population database for ACL reconstruction. Over the last 2 years (2008-2010), 13,941 primary ACL reconstructions were performed (annual incidence 13.5 per 100,000 English population). The majority of these patients were discharged within two days of surgery. It is a common perception that ACL surgery is a 'day case'. In

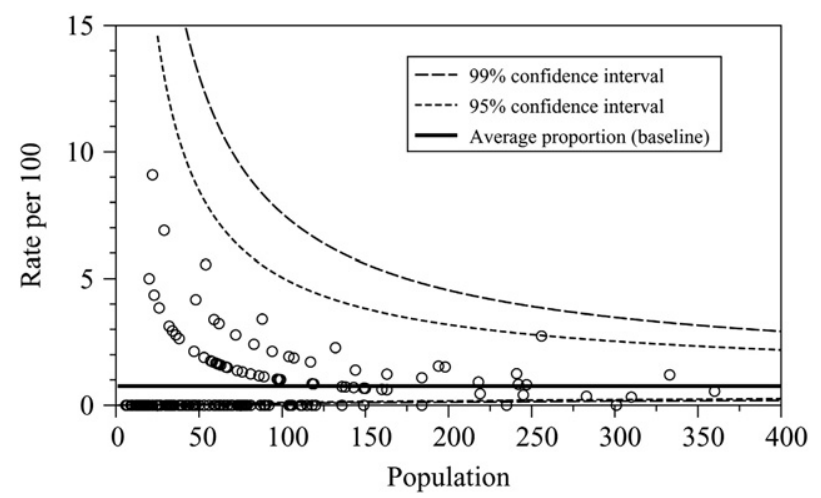

Fig. 5. Funnel plot of 30-day wound complications following ACL reconstruction in units providing care for English NHS patients.

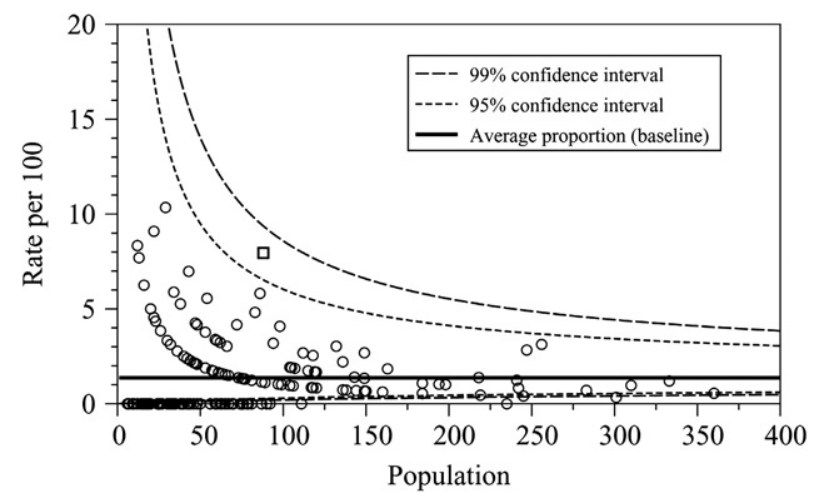

Fig. 6. Funnel plot of 30-day readmission following ACL reconstruction in units providing care for English NHS patients. 


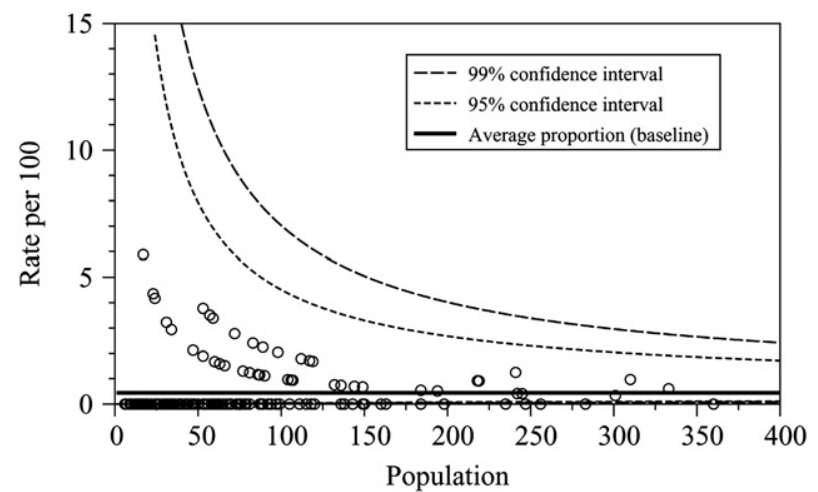

Fig. 7. Funnel plot of 90-day VTE event following ACL reconstruction in units providing care for English NHS patients.

fact, this data shows that only around 20\% are true day case procedures in the English NHS.

Rates of wound complications, early re-operation for infection and readmission were low and there were no deaths recorded. Infection is a rare complication after ACL reconstruction and ranges from $0.3 \%$ to $1.7 \%$, usually involving bacterial organisms [16]. This can range from superficial surgical site infection and minor wound complications to septic arthritis of the knee with devastating consequences. Lyman et al. [1] looked at complications post surgery and quoted a readmission rate within 90 days of $2.3 \%$. Our 30-day readmission rate was $1.4 \%$. However, there appeared to be more variance from the baseline in this data compared with other complications, with several units in the funnel plots straying towards the upper 95\% confidence limits. This data may be important in the future as English NHS Trusts are penalised for every readmission following elective surgery [17]. Our low infection rate combined with low return to theatre figures reassures and confirms that ACL reconstruction is a clean procedure. Unfortunately, other than infections, we lack data on cause of readmissions. This could suggest that we are underestimating wound complication rates, or simply that patients are presenting other complications that our analysis is unable to capture. Lyman et al. [1] also found that low volume units had significantly higher readmission rates. We found no such association with any of the complications investigated in this study.

There is a commonly held view that ACL surgery is not associated with VTE. This study has demonstrated that patients undergoing ACL reconstruction are at greater risk of VTE when compared with a nonsurgical population, but much lower than lower limb arthroplasty patients, and there were no fatal PTEs. Based on a middle-aged, female, non-surgical population, the general background risk of a VTE event was calculated as 0.058 per 1000 person months by Sweetland and colleagues [18]. For a 90-day ( 3 month) period this is the equivalent of $0.017 \%$ risk. VTE rates are therefore 26 times higher than the background risk (0.44\%) after ACL reconstruction. Jameson et al. [19] have previously shown that VTE risk (excluding out of hospital fatal PE rate) following lower limb arthroplasty is around $2 \%$, similar to the findings of Sweetland et al, and around 120 times higher than background risk (Fig. 3). It should be noted that over $95 \%$ of lower limb arthroplasty patients receive chemical thromboprophylaxis [20]. This data is unknown for ACL surgery, but is likely to be much lower.

Current guidelines from the statement of best practice in primary ACL reconstruction for an isolated rupture, approved by the British Orthopaedic Association, British Association for the Surgery of the Knee and British Orthopaedic Sports Trauma Association state that the risk of DVT following ACL surgery is very low and routine prophylaxis is not indicated [6]. NICE does not currently make any specific recommendations on thromboprophylaxis following ACL surgery, although there is guidance on lower limb elective surgery. This states that patients who undergo lower limb surgery lasting for more than

Table 3

Predictors of outcomes.

\begin{tabular}{|c|c|c|c|c|c|c|c|c|}
\hline & \multicolumn{2}{|l|}{ 90-day VTE } & \multicolumn{2}{|c|}{ 30-day wound complication } & \multicolumn{2}{|c|}{$\begin{array}{l}\text { 30-day reoperation } \\
\text { for infection }\end{array}$} & \multicolumn{2}{|c|}{ 30-day readmission } \\
\hline & OR (95\% CI) & P value & OR $(95 \% \mathrm{CI})$ & P value & OR $(95 \% \mathrm{CI})$ & P value & OR (95\% CI) & $P$ value \\
\hline \multicolumn{9}{|l|}{ Age } \\
\hline$<20$ & 0 & - & $\begin{array}{l}0.57 \\
(0.24,1.35)\end{array}$ & 0.195 & $\begin{array}{l}1.01 \\
(0.32,3.13)\end{array}$ & 0.989 & $\begin{array}{l}1.16 \\
(0.75,1.78)\end{array}$ & 0.509 \\
\hline $20-30$ & Reference & & Reference & & Reference & & Reference & \\
\hline $30-40$ & $\begin{array}{l}1.55 \\
(0.84,2.85)\end{array}$ & 0.152 & $\begin{array}{l}1.12 \\
(0.64,1.94)\end{array}$ & 0.688 & $\begin{array}{l}1.71 \\
(0.77,3.80)\end{array}$ & 0.185 & $\begin{array}{l}1.21 \\
(0.85,1.73)\end{array}$ & 0.277 \\
\hline$>40$ & $\begin{array}{l}2.36 \\
(1.29,4.34)\end{array}$ & 0.004 & $\begin{array}{l}1.22 \\
(0.66,2.25)\end{array}$ & 0.533 & $\begin{array}{l}1.51 \\
(0.60,3.85\end{array}$ & 0.381 & $\begin{array}{l}1.06 \\
(0.69,1.61)\end{array}$ & 0.794 \\
\hline \multicolumn{9}{|c|}{ Charlson score } \\
\hline 0 & Reference & Reference & Reference & Reference & Reference & Reference & Reference & Reference \\
\hline$\geq 1$ & $\begin{array}{l}0.97 \\
(0.35,2.66)\end{array}$ & 0.947 & 0 & - & 0 & - & $\begin{array}{l}0.94 \\
(0.52,1.70)\end{array}$ & 0.846 \\
\hline \multicolumn{9}{|l|}{ Sex } \\
\hline Female & $\begin{array}{l}1.47 \\
(0.84,2.57)\end{array}$ & 0.175 & $\begin{array}{l}0.54 \\
(0.27,1.08)\end{array}$ & 0.076 & $\begin{array}{l}0.50 \\
(0.17,1.42)\end{array}$ & 0.184 & $\begin{array}{l}0.50 \\
(0.32,079)\end{array}$ & 0.002 \\
\hline Male & Reference & & Reference & & Reference & & Reference & \\
\hline \multicolumn{9}{|l|}{ LOS } \\
\hline$<1$ day & $\begin{array}{l}0.82 \\
(0.42,1.60)\end{array}$ & 0.563 & $\begin{array}{l}0.66 \\
(0.32,1.35)\end{array}$ & 0.248 & $\begin{array}{l}0.78 \\
(0.29,2.09)\end{array}$ & 0.628 & $\begin{array}{l}0.98 \\
(0.67,1.44)\end{array}$ & 0.923 \\
\hline$>1<2$ days & Reference & & Reference & & Reference & & Reference & \\
\hline$>2$ days & $\begin{array}{l}0.63 \\
(0.31,1.31)\end{array}$ & 0.213 & $\begin{array}{l}1.52 \\
(0.91,2.55)\end{array}$ & 0.107 & $\begin{array}{l}1.49 \\
(0.69,3.18)\end{array}$ & 0.305 & $\begin{array}{l}1.14 \\
(0.80,1.63)\end{array}$ & 0.464 \\
\hline \multicolumn{9}{|c|}{ Provider volume } \\
\hline Low & $\begin{array}{l}0.72 \\
(0.29,1.77)\end{array}$ & 0.477 & $\begin{array}{l}0.97 \\
(0.44,2.14)\end{array}$ & 0.937 & $\begin{array}{l}0.52 \\
(0.14,1.91)\end{array}$ & 0.313 & $\begin{array}{l}1.43 \\
(0.90,2.29)\end{array}$ & 0.132 \\
\hline Mid & Reference & & Reference & & Reference & & Reference & \\
\hline High & $\begin{array}{l}1.02 \\
(0.56,1.85)\end{array}$ & 0.939 & $\begin{array}{l}1.15 \\
(0.65,2.03)\end{array}$ & 0.625 & $\begin{array}{l}0.98 \\
(0.45,2.12)\end{array}$ & 0.959 & $\begin{array}{l}1.23 \\
(0.85,1.78)\end{array}$ & 0.280 \\
\hline
\end{tabular}

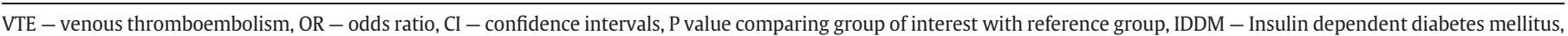

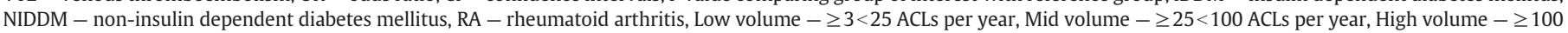
ACLs per year. 
60 min, including anesthetic time (defined as 'high risk'), may benefit from thromboembolic prophylaxis and should be offered both chemically and mechanically, although this lacks an evidence base (NICE 2010) [2]. However, there remains limited information on the incidence/risk factors for VTE following ACL surgery. Despite a thorough review of the literature we have found few reports from small case series of the incidence and outcome following symptomatic venous thrombosis after primary ACL surgery [5,21]. Other studies identified risk factors for VTE as being over 40 years of age and an operative duration greater than one hour [22]. Carlson et al. [23] reviewed 3200 cases with only seven reported PTEs, and found that 53\% of America Orthopaedic Society for Sports Medicine members used some form of VTE prophylaxis. In this analysis, age over 40 years was the only significant predictor of an increase in VTE risk, but there were no fatal in-hospital PTEs in any group. Statistical testing failed to identify an effect of any other variable on the complications analysed (other than sex on readmission, which is difficult to explain). However, it must be stressed that these adverse events are rare and the statistics in this situation have not been particularly helpful in stratifying risk.

The current knowledge of modern day ligament practice and outcome in England is based upon low uptake postal surveys [4,24]. There are limited, small case series [25-27] outlining case mix, outcome and major complications but there are significant drawbacks to such methods of data collection, such as poor response rates, nonvalidated questionnaires and a potential bias which can limit any conclusions that may be drawn [28]. They may also lack accurate representation of current practice [24]. In addition to these problems, outcome data derived from small number case series is difficult to interpret, as case selection does not accurately represent the normal burden of clinical practice, and there has been focus placed on surgical technique, timing of surgery and graft choice rather than outcome [25-27].

The most comprehensive data to date is derived from the national databases of Scandinavia. Established in June 2004, the Norwegian first two years recorded 2714 primary ACL reconstructions. Of these, 77\% received prophylactic anticoagulation and $5 \%$ encountered perioperative complications, 'most often due to graft failure' [29]. Interestingly the use of thromboprophylaxis ranged from 17\% in Denmark to $78 \%$ in Norway but no information on type, duration, or dosage was available [30]. Results from the first two years from the Danish registry looked at 4972 primary ACL reconstructions and quoted a perioperative complication rate of $4.3 \%$ [31]. Despite commenting on the use of thromboprophylaxis, there are no published VTE rates in any of the registries, nor was there data available on readmission rates or return to theatre for reoperation. Although these registries provide some insight into potential trends, there is limited information on breakdown of complications.

We accept that there are limitations within this observational study. We have no data on type or duration of the thromboprophylaxis regime. Nor were we able to comment on reasons for readmission other than infection. In addition, the data collection and coding of patients who are diagnosed with DVT as an outpatient may not be entirely accurate, and the figures presented here may in fact be an underestimate of the true 90-day DVT rate. Patients who die at home would not be detected in this analysis, but those who become unwell and subsequently die in hospital after readmission would be included. We acknowledge HES inaccuracies from the past [32], but the system is constantly improving and remains the most accurate means of large scale surgical data collection in England currently.

\section{Conclusions}

This study has quantified the complication rates for VTE, readmission and infection following ACL surgery from a national database. Infection rates are low with only one outlier for a 30-day reoperation.
Readmission rates vary considerably, with several units having higher than expected rates. Contrary to popular belief there is a real but small risk of VTE following ACL surgery. Whether this justifies thromboprophylaxis remains unanswered, given the lack of any real evidence in the literature for benefit. We believe this data strengthens the argument for a funded prospective ligament registry in the UK.

Supplementary materials related to this article can be found online at doi:10.1016/j.knee.2010.11.011.

\section{Acknowledgements}

Tony Roberts, Clinical Effectiveness Specialist Advisor, South Tees Hospital NHS Foundation Trust, for advice regarding the use of funnel plots

\section{References}

[1] Lyman S, Koulouvaris P, Sherman S, Do H, Mandl LA, Marx RG. Epidemiology of anterior cruciate ligament reconstruction. J Bone Joint Surg Am 2009;91:2321-8.

[2] National Institute for Health and Clinical Excellence. CG92 Venous thromboembolism reducing the risk: full guideline. http://www.nice.org.uk/nicemedia/ live/12695/47920/47920.pdf January 2010 (Section 5.9, p126 and Section 13, p269). Last accessed 27/10/2010.

[3] Allum R. Aspects of current management. Complications of arthroscopic reconstruction of the anterior cruciate ligament. J Bone Joint Surg Br 2003;85B: 12-6.

[4] Kapoor B, Clement DJ, Kirkley A, Maffulli N. Current practice in the management of anterior cruciate ligament injuries in the United Kingdom. Br J Sports Med 2004;38:542-4.

[5] Janssen RPA, Sala HA. Fatal pulmonary embolism after anterior cruciate ligament reconstruction. Am J Sports Med 2007;35(6):1000-2.

[6] Best practice for primary anterior cruciate ligament reconstruction. NHS Evidencemusculoskeletal. http://www.library.nhs.uk/musculoskeletal/viewResource. aspx?resID=61272 Last accessed 04/11/2010.

[7] The Information Centre. HES online. Last assessed 01/11/2010.

[8] Jameson SS, Augustine A, James P, Townshend D, Reed MR. Major complications following foot and ankle surgery - analysis using national hospital episode statistics. J Bone Joint Surg Proceedings in press.

[9] Connecting for Health. http://www.connectingforhealth.nhs.uk/systemsandservices/ sus Last assessed 24/10/2010.

[10] Connecting for Health. Pseudonymisation implementation policy. www.connectingforhealth.nhs.uk/systemsandservices/sus/delivery/pseudo Last accessed 04/11/2010.

[11] Charlson ME, Pompei P, Ales KL, Mackenzie CR. A new method of classifying prognostic comorbidity in longitudinal studies: development and validation. J Chron Dis 1987;40(5):373-83.

[12] Copyright (c) 2010. Re-used with permission of the Health and Social Care Information Centre. All rights reserved.

[13] Spiegelhalter DJ. Funnel plots for comparing institutional performance. Stat Med 2005;24:1185-202.

[14] Wilson EB. Probable inference, the law of succession, and statistical inference. J Amer Statist Assoc 1927;22:209-12.

[15] Bland JM, Altman DG. The odds ratio. BMJ 2000;320:1468.

[16] Muscolo DL, Carbo L, Aponte-Tinao LA, Ayerza MA, Makino A. Massive bone loss from fungal infection after anterior cruciate ligament arthroscopic reconstruction. Clin Orthop Relat Res 2009;467(9):2420-5.

[17] Kmietowicz Z. Hospitals will be fined for emergency readmissions, says Lansley. BMJ 2010;340:c3079.

[18] Sweetland S, Green J, Liu B, Berrington de González A, Canonico M, Reeves G, et al. Duration and magnitude of the postoperative risk of venous thromboembolism in middle aged women: prospective cohort study. BMJ 2009;339:b4583-91.

[19] Jameson SS, Bottle A, Malviya, Muller SD, Reed MR. The impact of national guidelines for the prophylaxis of venous thromboembolism on the complications of arthroplasty of the lower limb. J Bone Joint Surg Br 2010;92(1):123-9.

[20] National Joint Registry. 5th Annual Report. http://www.njrcentre.org.uk/NjrCentre/LinkClick.aspx?fileticket $=$ Da4\%2b2sUVa\%2fl\%3d\&tabid $=86 \&$ mid $=523$ Last accessed 23/10/2010

[21] Cullison TR, Muldoon MP, Gorman JD, Goff WB. The incidence of deep vein thrombosis in anterior cruciate ligament reconstruction. Arthroscopy 1996;12(6):657-9.

[22] Sherman OH, Fox JM, Snyder SJ, Del Pizzo W, Friedman MJ, Ferkel RD, et al. Arthroscopy-"no problem surgery". J Bone Joint Surg Am 1986;68:256-65.

[23] Carlson E, Steiner M, Brown C. Thromboembolic disease following arthroscopic anterior cruciate ligament surgery. Presented at the annual meeting of the American Orthopaedic Society of Sports medicine, Sun Valley, ID; 1993. July.

[24] Patel N, Chandratreya A, Radcliffe G, Bollen S. Current ACL practices in the UK: a postal survey of BASK members. J Bone Joint Surg Br 2008;90-B(SUPP_III):583.

[25] Deehan DJ, Salmon LJ, Webb VJ, Davies A, Pinczewski LA. Endoscopic reconstruction of the anterior cruciate ligament with an ipsilateral patellar tendon autograft. J Bone Joint Surg Br 2000;82(7):984-91.

[26] Pinczewski LA, Lyman J, Salmon LJ, Russell VJ, Roe J, Linklater J. A 10-year comparison of anterior cruciate ligament reconstructions with hamstring tendon 
and patellar tendon autograft: a controlled, prospective trial. Am J Sports Med 2007;35(4):564-74 Epub 2007 Jan 29.

[27] Webb JM, Corry IS, Clingeleffer AJ, Pinczewski LA. Endoscopic reconstruction for isolated anterior cruciate ligament rupture. J Bone Joint Surg Br 1998;80(2): 288-94.

[28] Edwards P. Questionnaires in clinical trials: guidelines for optimal design and administration. Trials 2010;11:2.

[29] Granan LP, Bahr R, Steindal K, Furnes O, Engebretsen L. Development of a national cruciate ligament surgery registry: The Norwegian National Knee Ligament Registry. Am J Sports Med 2008;36(2):308-15.
[30] Granan LP, Forssblad M, Lind M, Engebretsen L. The Scandinavian ACL registries 2004-2007: baseline epidemiology. Acta Orthop 2009;80(5):563-7.

[31] Lind M, Menhert F, Pedersen A. The first results from the Danish ACL reconstruction registry: epidemiologic and 2 year follow-up results from 5, 818 knee ligament reconstructions. Knee Surg Sports Traumatol Arthrosc 2009;17: $117-24$.

[32] Westaby S, Archer N, Manning N, Adwani S, Grebenik C, Ormerod O, Pillai R, Wilson N. Comparison of hospital episode statistics and central cardiac audit database in public reporting of congenital heart surgery mortality. BMJ 2007;335 (7623):759. 